Rev. Latinoam. Psicopat. Fund., São Paulo, 18(2), 204-220, jun.2015

http://dx.doi.org/10.1590/1415-4714.2015v18n2p204.2

\title{
Conferência
}

\section{Paixão-dor-paixão: pathos, luto e melancolia no nascimento da criança com deficiência*1}

\author{
Vitor Franco*2
}

O nascimento de um filho com um transtorno grave de desenvolvimento marca, enquanto crise, o percurso evolutivo dos pais. A perda do bebê idealizado, exige um trabalho de elaboração do luto. No entanto, a ligação emocional ao pathos-paixão inicial ergue-se como obstáculo a esse processo e, mais do que isso, à criação de um novo vínculo ao bebê nascido e real, com as suas qualidades e limitações, que corre o risco de não ocupar um espaço na vida emocional dos pais a contas com o seu pathos-dor. Neste trabalho serão discutidas as saídas do lado melancólico e as alternativas de elaboração do sofrimento emocional com vista ao investimento parental e apego à criança com deficiência.

Palavras-chave: Deficiência, apego, melancolia, luto

*1 Texto desenvolvido para a comunicação apresentada no VI Congresso Internacional de Psicopatologia Fundamental em Belo Horizonte, Brasil, em setembro de 2014.

*2 Universidade de Évora (Évora, Portugal). 


\section{CONFERÊNCIA}

Os transtornos de desenvolvimento e a deficiência são temas que habitualmente concitam pouco interesse dos pesquisadores. Podemos dizer que se trata de percursos de vida marcados pelo pathos, em ambos os sentidos, patologia e paixão, que não se podem entender separadamente.

O pathos-patologia é que nos leva a evitar a temática da deficiência pois nos fala da imperfeição, da incapacidade, e da própria morte e, por isso, é assustadora, acabando por ser um obstáculo à inclusão dessas pessoas. Por outro lado, o pathos-paixão é geralmente desconsiderado, o que cria dificuldade na compreensão do que acontece com os pais destas crianças, a sua vida mental, e os papéis parentais, impedindo a ajuda efetiva na retomada do seu desenvolvimento saudável.

Aliás, em todo esse percurso quase sempre se ignora o que acontece do lado dos pais, especialmente da mãe, perspectiva geralmente menos desenvolvida pela metapsicologia psicanalítica em desfavor do que acontece do lado da criança. Sabendo, no entanto, que um e outro lado se interligam continuamente e se constroem nessa ligação.

Ora, um acontecimento emocional desta envergadura, que é o nascimento - ou o diagnóstico — de um filho com deficiência grave, é um desafio ao desenvolvimento do Eu, ao desenvolvimento dos pais, que não pode ser encarado apenas sob a perspectiva da patologia (ou do pathos-patologia) que nos conduziria à patologização da condição. É, aliás, essa mesma a colocação de Freud (1917/1992), ao escrever sobre luto e melancolia, em que pensa essencialmente sobre o Eu na perspectiva da não diferenciação entre o normal e o patológico, acentuando que tristeza e depressão não são sinais de presença ou ausência de normalidade, mas apenas de que há um trabalho em curso operando a perda do objeto e uma remodelagem do Eu (Rivera, 2012).

Assim, vamos procurar fazer um percurso em três atos, a que chamaremos paixão, dor e, de novo, paixão. Procurando mostrar como o pathos, no seu duplo sentido, está presente em todo o percurso até ser adequadamente elaborado e ser retomada a saúde desenvolvimental.

Rev. Latinoam. Psicopat. Fund., São Paulo, $18(2)$, 204-220, jun. 2015 


\section{Ato 1 - Paixão}

A compreensão da história de desenvolvimento destas crianças nas suas famílias, obriga a recuar até aos primeiros momentos da sua existência. E todas elas começaram por existir antes do nascimento, ou até mesmo antes da concepção, pois todo o bebê "nasce no pensamento dos pais, muito antes do momento do parto, sempre e quando estes são capazes de o imaginar" (Sá, 1996).

Aí se inicia aquilo a que Brazelton \& Cramer (1989) chamam a pré-história do apego, responsável pela criação dos laços mais precoces e fundamentais que permitem aos pais tornarem-se uma família cuidadora e amorosa para a sua criança. É a idealização do filho imaginário que vai preparando a família para um bebé real que irá nascer.

\section{O bebê imaginado}

É preciso ser "louco" para desejar ser pai ou mãe de um bebê. Para desejar estabelecer uma relação que é inconcebível em qualquer outra circunstância. Podemos perguntar-nos quem estaria disponível para assumir uma relação com 206 alguém que chora de hora a hora pedindo comida, que quando queremos descansar quer brincar; quando queremos brincar quer dormir, é instável, cheira mal, grita e chora inesperadamente, é preciso limpar e cuidar permanentemente. No entanto, nós humanos, desejamos e congratulamo-nos com essa relação quando se trata dos bebês, embora em nenhuma outra situação estejamos disponíveis para tal tipo de relação de forma continuada.

Este é o pathos que nos permite ser pais: a paixão por um filho que vai nascer. Em que o narcisismo brota e a criança é o lago em que nós, narcisos, nos queremos mirar, já que, como disse Helen Deutsch (1945) “a maternidade [e paternidade] não é apenas um processo biológico mas também uma experiência psicológica única, através da qual é dada à mulher [e ao homem] a oportunidade de experimentar um sentido real de imortalidade" (apud Pedro, 1985, p. 35).

Ora, é fundamental reconhecermos que todas as crianças com deficiência nasceram perfeitas na imaginação dos seus pais. Pelo que, para as compreendermos, e às suas famílias, não podemos ignorar esse período fundamental nas suas vidas. Observemos então o que aconteceu nessa fase, nesse primeiro momento de paixão, para compreender o que vai acontecer depois.

Durante a gravidez, no psiquismo da mãe (e também do pai) vai se formando uma ideia de ser mãe/pai e a construção da imagem mental do bebê (Stern, 1997) podendo assumir que há três gestações simultâneas (Stern, Brunschwiler-Stern \& Freeland, 1999) sendo que uma delas é precisamente a formação do bebê imaginado 


\section{CONFERÊNCIA}

ou, como também diz Aulagnier (1990), uma gestação que se faz ao nível biológico e ao nível da relação de objeto.

Assim sendo, o início da gravidez é de um marcado narcisismo, pois esse bebê imaginado, construído pelos pais, existe como parte deles mesmos e como objeto. Embora o desenvolvimento do feto e do bebê imaginado não ocorram paralelamente e Stern (1997) defenda que há intensificação da idealização do bebê a partir do quarto mês a qual atinge o seu máximo por volta do sétimo mês de gestação.

Podemos designar esta ligação de várias formas: como uma pré-vinculação, ou vinculação pré-natal (Condon, 1985; Teixeira, 2013), vinculação ao bebê imaginário Lebovici (1987) ou pré-história da vinculação (Brazelton \& Cramer, 1989). Não se trata ainda de apego no sentido definido por Bowlby (1969), nem uma verdadeira relação interpessoal, pois o bebê real ainda não é conhecido nem se impõe na sua realidade, podemos situar aí o início de uma relação, pois o bebê imaginado permite à mãe entrar em relação antes do bebê nascer ou se dar a conhecer totalmente. Ela personifica-o, situando-se aí as raízes do "apego primordial".

Os desejos narcisistas dos pais são fundamentais para a construção do filho imaginado e por isso ele se torna um bebê idealizado. E são estes desejos narcisistas que, colocados sobre o bebê, preparam a mãe para se vincular à futura criança (real) suportando as suas exigências. Ou seja, é a dimensão da idealização, pelo seu caráter narcísico, que permite uma relação que podemos chamar "louca". Refere Hornstein (1994) que o bebê imaginado permite à mãe inseri-lo numa ordem de coisas da qual ela também faz parte, sendo este corpo imaginado que permitirá que a mãe invista libidinalmente o seu bebê, reconhecendo-o como corpo separado. Um investimento da libido no bebê imaginado que se vai intensificando como num enamoramento (Bydlowski, 2000), uma paixão. A idealização é precisamente esse estado de considerar o outro como perfeito, ideal e lhe atribuirmos qualidades de acordo com isso, exaltando-o e apaixonando-nos por ele.

Embora no seu início o objeto não difira do $\mathrm{Eu}$, faz parte dele. A mãe parte de um objeto idealizado para que surja um bebê real privilegiado (separado do eu) em que o objeto nascido na fantasia pode deixar-se amar e desejar. Este bebê imaginário é construído, pelos pais, a partir de três componentes fundamentais que não são alheios às suas representações e objetos internos ou suas experiências de vida.

Em primeiro lugar, uma componente estética: o bebê ideal tem características de perfeição física e estética, incorporando semelhanças com os pais, mas sempre atingido por padrões estéticos elevados. Sendo bonita, corresponde ao bebêé perfeito, sorridente, gordinho, com boas cores, limpo e ativo, que vemos na publicidade. O corpo imaginado do bebê representa a primeira inserção no mundo imaginário e é o que dá a possibilidade de libidinizar o corpo enquanto separado do próprio (Ferrari, 2003, p. 44) e inserido na mesma ordem humana. 
Em segundo, uma dimensão de competência em que o bebê se imagina e espera como intelectualmente competente, pleno de capacidades que correspondam ao estilo de vida e valores dos pais. Um bebê que personifica os desejos e fantasias maternas e paternas e, assim, se liga mesmo às mais arcaicas e infantis. Que será tão bom quanto os melhores aspectos dos seus pais, mas sempre ainda um pouco melhor que eles, pois assim eles cuidarão que seja.

Finalmente uma dimensão de futuro. Os pais imaginam um futuro ideal para essa criança, que um dia cursará os seus estudos, será um profissional de sucesso e realizado, terá um certo tipo e nível de vida, e os deixará felizes e realizados como pais. O bebê é pensado como o que fará o que não pôde ser feito, e reparará o que não foi reparado na vida destes pais.

Como dissemos, é o bebê idealizado que dará substrato psíquico para a mãe entrar em relação com o bebê real. O imaginado dá vida ao real, diz Aulagnier (1990). Tem assim uma função fundamental, já que é ele que permite que os pais se vão preparando para entrar em relação com a criança que está para nascer (Stern, 1997; Stern, Brunschwiler-Stern \& Freeland, 1999; Aulagnier, 1990). Ao mesmo tempo, é ele que promete cuidar do Eu dos seus pais tornando-os melhores aos seus próprios olhos, vencendo as angústias e medos da gravidez e da paternidade.

Assim, estas dimensões imaginárias e idealizadas são fundamentais para que os pais possam suportar as exigências colocadas pelo cuidar de um bebê. Paradoxalmente, é o bebê perfeito, nascido dentro de cada pai e cada mãe, que lhes permite cuidar de um bebê que não é, de forma alguma, perfeito, mas requer atenção, é instável, suja-se, grita, exige e frustra. A idealização é pois imprescindível para o apego precoce. É a capacidade de vermos o bebê como completamente bom que nos aproxima dele, nos permite apaixonar por ele e projetar nele os nossos desejos, necessidades e esperanças.

Quando este pré-vínculo não se constrói, ou seja, os pais não conseguem imaginar os seus filhos, esses bebês incorrem no risco de abandono físico ou emocional, negligência ou falta de cuidados adequados. As crianças que não nasceram na imaginação dos seus pais são crianças sem um lugar para nascer, crescer e se desenvolver e, por isso, são crianças emocionalmente abandonadas. Só crianças sonhadas como bonitas, perfeitas, competentes e com um promissor futuro diante de si podem ser cuidadas pelos seus pais. Mesmo que nem todas as crianças comecem por ser desejadas, todas precisam ter um lugar emocional para nascer, criado pelos seus pais, dentro de si, na relação e no cuidar. Mesmo que o destino da idealização seja o desapontamento, ou seja, o reconhecimento do outro como completo, diferente de nós e imperfeito. É a desilusão o que permite lidar com a subjetividade do outro.

O apego é assim um laço, uma ligação, que nos permite ser "loucos". É este pathos-paixão que nos prepara para sermos pais e nos permite sê-lo. 


\section{CONFERÊNCIA}

Se esta é a história fundamental de cada criança, a base e a pedra-chave do seu desenvolvimento, este é também o princípio da história de vida de cada criança com deficiência. Todas as crianças com deficiência nasceram, um dia, na imaginação dos seus pais, como crianças perfeitas, competentes e promissoras. Todas nasceram, na sua fantasia e no seu desejo, como ideais e capazes e com um futuro pela frente.

Toda a criança com deficiência nasceu perfeita e ideal, de um pai e mãe perfeitos que, no seu filho, podiam ser ainda mais perfeitos.

\section{Ato 2 - Dor}

\section{Crise e elaboração do sofrimento emocional}

Ao nascerem com uma deficiência, ou quando essa alteração grave do seu desenvolvimento é identificada, há uma ruptura do percurso de desenvolvimento dessa criança, da sua família e da ligação entre ambos. O diagnóstico comunicado se traduz frequentemente nisto: "O filho que imaginou e idealizou não existe, mas sim este bebê que tem um problema".

Dizem alguns que, perante isto, é inevitável a depressividade crônica, o luto crônico, ferida narcísica insuperável reaberta pela presença constante da criança. Porque no amar aquele filho que ainda não existia estava o Eu que, assim, fica posto em causa.

Demasiado simplista para estar certo. A questão fundamental é que o objeto de amor destes pais desapareceu, mas não basta que ele desapareça para que se faça o trabalho psíquico da perda (o trabalho de luto). É neste segundo momento, no processo de desenvolvimento de um vínculo, que se dá a crise, ou seja, a ruptura. Nada mais será como dantes e nada será como tinha sido imaginado e esperado. Tal significa bem mais do que mais trabalho, novas dificuldades, ou novas necessidades e exigências. É uma crise, ou seja, nada voltará a ser igual e toda uma perspectiva de vida, de presente e futuro, tem de ser mudada pois já não se adequa à realidade. Não se trata de uma simples perturbação, disfuncionamento, emergência ou problema a ser resolvido, de um ajustamento a ser feito com os recursos que tem disponíveis, ou algo que tem de se aceitar.

Para estes pais, ao nascer uma criança com uma deficiência grave, algo de fundamental é posto em causa, englobando uma grande diversidade dos fatores que caracterizam cada situação. O retomar do desenvolvimento, que é também a saída da crise, não passa por "aceitar" a nova situação. Aceitação tem um sentido passivo, de inevitabilidade e de resignação, e não de organização da vida mental e relacional. O que vai estar em causa, nestes pais, são os meios que vão utilizar e os movimentos que vão fazer para tentar retomar o seu curso de desenvolvimento. 
Um vasto conjunto de comportamentos tem a ver com a expressão emocional do sofrimento que a situação trouxe. Muitos destes movimentos estão interligados ou mascarados, como, por exemplo, a revolta, raiva, negação, culpabilização ou os sentimentos depressivos.

\section{Melancolia e manutenção do objeto idealizado}

A negação é um movimento inevitável e fundamental face ao impacto do diagnóstico da existência de uma perturbação grave do desenvolvimento. Do ponto de vista pragmático leva a que os pais não fiquem passivos e resignados perante um diagnóstico tão doloroso, e os faz buscar segundas opiniões, especialistas mais qualificados e técnicos mais competentes. No entanto, a negação pode ter formas mais destrutivas quando os pais negam a realidade e colocam a criança sem ter assistência nem cuidados porque, supostamente, deles não necessita, ou esperar para ver o que acontece, perdendo muitas vezes o tempo ótimo para uma intervenção mais promissora porque mais precoce. A negação pode até ter formas mais dissimuladas e aparentemente benévolas, como os pais que se afadigam durante anos em procurar soluções milagrosas, num aparente interesse pela sua criança, e que também podem estar, dessa forma, fugindo e negando a realidade.

A negação é, nesta situação, a manutenção da ligação ao objeto idealizado. É dizer que o bebê idealizado e o bebê real são o mesmo objeto e que há continuidade entre eles. Que não é necessário transformar, perdendo e refazendo um novo objeto.

A negação fundamental não se refere à negação da realidade da criança em si. Refere-se à tentativa de negar a descontinuidade entre o bebê idealizado e a criança real. Acontece sempre que o interesse pela criança alimenta a ilusão de que, com um pouco mais de terapia, de esforço de educadores, de apoios de algum tipo, a criança real pode corresponder à criança idealizada. A negação é também a negação do desaparecimento do bebê imaginário e da sua idealização.

O discurso de revolta e da raiva, contra tudo e todos, é quase sempre a resposta inicial. Revolta e raiva dirigida contra os médicos, profissionais de saúde, familiares ou amigos que alguma coisa fizeram (ou não fizeram) contra os que parecem não compreender ou não ser suficientemente solidários e empáticos. Corresponde a pôr em causa tudo, incluindo até uma inquietação existencial de revolta contra Deus, o destino ou a sorte, que de forma tão dura parece ser responsável pela destruição de algo bom e idealizado. Que o discurso dos pais sobre a criança e o seu desenvolvimento tenha uma componente de revolta e raiva é inevitável e está presente em todas as famílias, mas já a manutenção da revolta como elemento emocional preponderante, ao longo dos anos, é um mau preditor do bom desenvolvimento dos pais e, principalmente, da qualidade do apego. Pianta, Marvin 


\section{CONFERÊNCIA}

\& Morog (1999) mostraram que a manutenção de um discurso marcado pela revolta está inversamente correlacionado com o desenvolvimento da vinculação entre pais e criança. Ou seja, o elemento de revolta e raiva está ainda na esfera da elaboração da perda da idealização e, portanto, ligado ao bebê idealizado e ao sofrimento causado por ter sido posta em causa. Por isso, mesmo quando esta revolta parece ter uma dimensão legítima de interesse pelos filhos e defesa dos seus interesses, e se manifesta por um litígio permanente com os profissionais ou serviços que lhe dão apoio, frequentemente estamos perante pais ou mães com dificuldades de elaboração da perda e, consequentemente, perante famílias que têm maior dificuldade em estar disponíveis, e disponibilizar os seus recursos emocionais para o filho real, a criança concreta com a sua deficiência.

A atribuição de culpa é outro dos fatores mais presentes neste processo, quase sempre aliado à revolta e à negação. A culpa tem consequências destrutivas sendo sempre um obstáculo ao retomar do processo de desenvolvimento. Pode tratar-se da culpa atribuída aos médicos ou outros técnicos que estiveram presentes nas fases pré ou perinatal, ou associados ao momento do diagnóstico, e a manutenção dessa culpabilização representa sempre algum tipo de fixação no bebê idealizado, e nestes casos liga-se diretamente à revolta. Pode ser também a culpabilização do cônjuge, que tem frequentemente efeitos muito destrutivos, porquanto implica uma atribuição causal relativamente à deficiência que, muitas vezes, é irracional e se estende até às gerações anteriores. A sua destrutibilidade é sempre muito grande em relação ao funcionamento ou coesão familiar, assim como ao bem-estar emocional. Muito frequentemente encontramos ainda formas de autoculpabilização, que não permitem um retomar saudável do seu desenvolvimento, pois o abdicar do bebê imaginário não parece possível pela presença dessa ferida da culpa.

Também o mal-estar depressivo é compreensível numa situação como esta, de profunda perturbação emocional. Mais do que isso, o sofrimento depressivo é inevitável pois o que está em causa é, antes de mais nada, uma perda: do bebê idealizado, com tudo o que ele representa. Questão diferente é a da existência de depressão crônica nestas famílias. Embora alguns autores afirmem a sua inevitabilidade, fazem-no mais com suporte num modelo teórico (a existência de uma ferida narcísica irreparável) ou em estatísticas que mostram a maior incidência de situações depressivas nestes pais. Nenhuma delas nos permite, por si só, validar essa perspectiva e encontramos oscilações significativas das situações depressivas ao longo do tempo, dependendo da capacidade de pais e mães elaborarem os seus sentimentos depressivos e de retomarem a sua conflitualidade emocional prévia.

Chegamos assim à questão fundamental da melancolia. $\mathrm{O}$ que temos, nestes processos, é aquilo que caracteriza a melancolia: identificação com o objeto perdido (a ponto de se perder com ele). Em vez de encetar o luto pelo objeto perdido (o 
bebê ideal), o Eu se revolta contra a perda e contra os outros. Daí que a revolta esteja no cerne da melancolia que se instala, criando uma dor, ferida permanentemente aberta que suga a libido.

$\mathrm{Na}$ melancolia "o Eu se torna como objeto de crítica e de mortificação graças a uma identificação com o objeto perdido" (Rivera, 2012). Por isso, há um caminho de inevitável empobrecimento do Eu, que leva a que estas pessoas corram risco de múltiplo empobrecimento (econômico, cultural, social/relacional e egoico).

Nesta melancolia, a ausência do bebê idealizado não produz significante, mas sim vazio. "Diante a ausência, ou a inadequação da resposta recebida, produz-se uma discordância no vínculo, um movimento sem efeito subjetivo, um significante que cai no vazio" (Humphreys, 2013). Trata-se da perda de um objeto que leva em si a projeção do ideal do Eu do sujeito e, portanto, do seu próprio investimento narcísico (Asséo, 2003).

Podemos encontrar então facilmente a presença da vergonha e da culpabilidade que, para Freud (1917/1992), permitem diferenciar, de um ponto de vista psicopatológico, a crise aguda de melancolia, de outras formas de manifestação depressiva. Também para Fédida (1978) nos diz que

(...) a escuta da queixa melancólica deixa frequentemente de lado a dimensão da angústia de um Eu que se sente incapaz de sobreviver perante a ideia do desaparecimento do objeto de amor. Por isso parece aceitável pensar que a libido que não pôde ser investida sobre um outro objeto de substituição seja retraída sobre o Eu, levando a identificação do Eu ao objeto abandonado, e a agressividade ligada à angustia da perda do objeto de amor se manifesta numa espécie de canibalismo melancólico capaz de destruir o objeto para não se separar dele. O luto impossível do melancólico consistiria assim na união canibalística incestuosa a um objeto cujo desaparecimento pode ser conhecido (no registro do que se sabe) mas não crida (unindo para sempre o melancólico ao cadáver do seu objeto). O objeto perdido mantém-se assim fantasmaticamente vivo. (p. 65)

Humphreys (2013) diz-nos que "se a depressão constitui uma organização narcísica a proteger do luto, na qual o sujeito se vê mobilizado pela presença da ausência, a melancolia seria o pôr em ação a violência da fascinação pelo objeto de amor que não pode ser reconhecido como morto, mas sim devorado por uma espécie de assassinato canibálico da beleza — mais que da bondade — associada à morte" (p. 406).

A mania seria outra saída tentada para a melancolia, aflorada por Freud (1917/1992): suspensão da perda pela entrega maníaca ao objeto, presente nas palavras dos pais quando referem "foi a melhor coisa que me aconteceu!", "foi uma dádiva de Deus", acompanhados de exaltação e agitação. 


\section{CONFERÊNCIA}

Face a esta situação de crise e de perda, a questão passa a ser então: que faz esse pai ou essa mãe, face a dois grandes caminhos: ficar de alguma maneira ligada à fase anterior e ao bebê imaginário ou, então, organizar o seu luto por ele.

\section{Elaboração de perda e o sofrimento emocional}

Para prosseguir o seu processo de desenvolvimento tem de ser feito o luto pela perda sofrida: a perda do bebê idealizado. O luto refere-se ao processo, ao longo de um determinado período, em que a pessoa elabora a sua perda. Um trabalho lento e doloroso, em que o Eu renuncia ao objeto e se afasta pulsionalmente dele.

Temos então uma desilusão. No sentido em que o bebê imaginário nunca chegou a nascer, ou melhor, desapareceu num determinado momento. Já não se trata apenas do desapontamento, destino normal de evolução da idealização à realidade. Pelo contrário, o bebê que nasceu com deficiência corresponde às maiores angústias e ansiedades que, muito provavelmente, acompanharam a gravidez. A desilusão funda o luto e a perda dos objetos relacionais é sempre, como vimos, acompanhada de dor mental e de sofrimento emocional.

O que aqui se perdeu não foi a pessoa, o bebê, mas o objeto construído, interno, idealizado, com o qual o processo vinculativo começou a ter lugar. E não basta que o objeto desapareça para haver separação dele, é necessário o trabalho psíquico sobre a perda. O desenvolvimento do Eu pode ser visto como um trabalho de perda do objeto (Rivera, 2012) no mesmo sentido da posição depressiva de Melanie Klein. É pois um processo em que o Eu se transforma e se refaz no jogo com o objeto (Rivera, 2012).

\section{Ato 3 - Paixão}

\section{Reidealização}

No entanto, com o luto não está terminado o percurso que descrevemos. Este processo de luto é diferente de outros no que se refere ao desaparecimento da representação do objeto e do próprio objeto. O problema que temos aqui é de natureza diferente, já que há uma criança que permanece. Por isso, o processo não termina no processo de luto e na sua elaboração, pois a questão fundamental passa a ser o que fazer com a criança. Como se pode estabelecer um vínculo, uma ligação, com essa criança que não foi desejada, não foi imaginada nem esperada. Não se trata de restabelecer ou recuperar um vínculo, mas de criar um vínculo com "outra" criança. 
Aqui temos de nos socorrer de novo da teoria. Se a premissa que todas as crianças nascem primeiro na idealização dos pais, e, mais do que isso, é essa idealização que lhes dá possibilidade de existirem e serem cuidadas, a questão nuclear no desenvolvimento destes pais e da criança não é o luto, mas o que se lhe segue. Se o que foi idealizado não nasceu, pois era o "outro", há agora uma criança a ser cuidada e investida emocionalmente como filha.

Há um conjunto de pais que podemos chamar funcionais, ou seja, pais que, em virtude do seu sofrimento emocional, não podem mais do que tratar do seu filho, não podendo exercer uma verdadeira e completa parentalidade, apenas podendo ser cuidadores de uma criança que exige mais do que as outras. Esses pais estão dominados pela ação e não pela relação parental. Todas as suas forças e recursos passam a estar ao serviço das necessidades da criança que deles carece, não vivendo os verdadeiros vínculos que pressupõem bidirecionalidade e envolvimento emocional mútuo e recíproco.

No entanto, a criança real também tem de ser reidealizada (Franco, 2009), ou seja, magnificada e fantasiada na imaginação dos pais e no seu desejo em relação a ela. A reidealização pressupõe sempre o não retornar à idealização inicial, abdicando de qualquer movimento visando a sua manutenção ou sobrevivência. Representa, por isso, a possibilidade de investir emocionalmente o bebê real e deixá-lo percorrer o caminho que se considera essencial para toda e qualquer criança.

Questão fundamental é compreender a natureza desta idealização. Se a inicial assentava sobre o bebê ideal, esta confronta-se com o bebê real e as suas características. Representa, por isso, a fertilidade emocional dos pais que se tornam capazes de pensar sobre ele tal como ele é e como poderá ser, e não como poderia ter sido. É esta fertilidade emocional que pode dar às crianças um lugar para nascer. Não o esforço, dedicação ou sacrifício dos seus pais. Nem o apoio social nas tarefas práticas a realizar, por si só. Crianças, filhas de pais funcionais, seriam crianças emocionalmente descuidadas, assistidas mas não investidas na promoção do seu desenvolvimento.

Sem reidealização temos, apenas, pais funcionais, ou seja, cuidando das suas crianças com base no seu esforço e estratégias de coping e procurando apoio. Mas não pais amorosos e emocionalmente envolvidos que é o que define a parentalidade e a criação de laços e vínculos imprescindíveis ao desenvolvimento da criança. Como diz Blatt (2008) são as experiências de conexão (engagement) e de quebra da conexão (disengagement) na interação mãe-criança que conduzem à formação das representações de self e dos outros, à capacidade de autorregulação e de inter-regulação. 


\section{CONFERÊNCIA}

A reidealização implica um segundo nascimento da criança. Ao invés do que acontece habitualmente, um nascimento que se deu primeiro na realidade e depois na imaginação dos pais.

\section{Dimensões da reidealização}

Podemos interrogar-nos sobre as características e condições para tal investimento emocional. $\mathrm{O}$ que foi dito anteriormente em relação à idealização em geral também é aplicável para a reidealização destas crianças. Também continuam a poder identificar-se três dimensões: uma estética, uma ligada às competências e outra ligada à temporalidade (perspectiva temporal futura).

A possibilidade dos pais da criança olharem para ela e acharem-na bonita é uma dimensão fundamental da constituição do vínculo. O ditado português "quem o feio ama bonito lhe parece" remete-nos para a verdade estética do vínculo. Esta dimensão estética está ligada à vertente narcísica da paternidade: a possibilidade dos pais mostrarem aos outros o seu filho, que veem como bonito, esperando que do outro lado haja o mesmo reconhecimento de beleza. É esta dimensão da reidealização que pode impedir que muitas crianças sejam retidas em casa, pelos seus pais, a salvo do olhar dos outros e também o que permite o seu cuidado estético para além do funcional. Que não sejam apenas bem alimentados ou tenham as terapias certas, mas alvo de tudo aquilo que, de aparentemente supérfluo, todos os pais querem dar aos seus filhos para que fiquem bonitos, sejam vistos como bonitos e gostem deles.

A segunda dimensão, a relativa às competências e capacidades é a que, por definição, se encontra afetada nestas crianças. A falta de capacidades ou competências é o que concretiza a sua situação de portador de deficiência. Quando se defende que o trabalho educativo com estas crianças se deve centrar no que elas são capazes de fazer, e não naquilo que não são capazes, estamos a referir-nos a muito mais do que um modelo, ou técnica de trabalho. A possibilidade dos pais (como também os técnicos) reconhecerem as competências dos seus filhos com deficiência é fundamental nesta reidealização. $\mathrm{O}$ pai ou a mãe da criança deficiente motora não a poderá mais idealizar como a grande desportista que porventura idealizou no passado; mas se a conhecer e compreender as suas competências pode, agora, idealizá-la talvez como medalhista nos jogos paraolímpicos, e assim mesmo uma grande desportista. Esta idealização não é, para estes pais, menos mobilizadora do que para outros que pensaram que um dia os seus filhos seriam grandes músicos, desportistas, médicos ou homens de negócios. O que está em causa é a capacidade de idealizar a partir da não negação, ou seja, a partir da realidade que se conhece neste momento, na sua realidade atual e nos seus limites futuros. A inclusão educativa, 
social, desportiva ou cultural destas crianças só faz sentido, só pode acontecer, se alguém, para elas, for capaz de idealizar, desejar algo de bom, belo e exigente, tendo em conta a sua realidade, mas desejando muito para além dela. O limite é sempre o mesmo: o de não cair em negação que seria, de novo, voltar à idealização original, ao outro, à criança que não nasceu.

A dimensão futuro adquire-se assim: na possibilidade de pensar o futuro. Frequentemente os pais destas crianças vivem localizados num presente que tudo domina, e têm grande angústia relativamente ao futuro, tanto seu como dos seus filhos. Mas o futuro é, por definição, a dimensão do que se espera, da esperança e do desejo. Podermos pensar sobre o futuro é alimentar possibilidades, alimentar esperança. Estes pais, como todos os outros, não podem saber o que vai acontecer no seu futuro e no dos seus filhos. A paralisia operacional seria a incapacidade de pensar sobre isso que acompanha os sentimentos de inutilidade, impossibilidade helpless (incapacidade de se defender ou agir sem ajuda) e melancolia. Muitas vezes os pais, ou as mães, dizem que a sua realidade é tão difícil que apenas podem pensar e enfrentar o dia a dia (um dia de cada vez). Mesmo assim são esses que têm, muito frequentemente, na sua vivência, mais dimensões de esperança. Que pode advir do acreditar em si mesmo, das suas convicções religiosas ou ideológicas, quanto mais não seja para não se sentirem esmagados emocionalmente pelo presente.

É então a reidealização que permite retomar o processo de desenvolvimento dos pais na relação com o seu filho com deficiência, que pode tornar-se agora, ele mesmo, objeto de investimento (e sobreinvestimento) libidinal. Idealização que está de novo ligada à paixão e à projeção nela de valores ideais.

Um desafio que requer tempo, mas em que o tempo é cada dia menor. Pois também esta idealização está destinada a ser desidealizada e, por isso, também ela será transitória, mas permite que aqueles pais retomem o seu desenvolvimento normal, não ficando bloqueados no pântano da sua melancolia.

\section{Referências}

Asséo, R. (2003). Quelques remarques préliminaires à l'extension du terme de "mélancolie". Revue Française de Psychanalyse, 67(5), 1549-1552.

Aulagnier, P. (1990). Um intérprete em busca de sentido. São Paulo: Escuta.

Blatt, S.J. (2008). Polarities of experience: relatedness and self-defining in personality, development psychopathology and therapeutic process. Washington DC: American Psychological Association.

Bowlby, J. (1969). Attachment. London: Hogarth.

Brazelton, T., \& Cramer, B. (1989). A relação mais precoce. Lisboa: Terramar. 


\section{CONFERÊNCIA}

Bydlowski, M. (2000). La dette de vie - Itinéraire psychanalytique de la maternité. Paris: PUF.

Cintra, E. (2011). Sobre luto e melancolia: uma reflexão sobre o purificar e o destruir. $A L$ TER - Revista de Estudos Psicanalíticos, 29(1), 23-40.

Clements, M., \& Barnett, D. (2002). Parenting and attachment among toddlers with congenital anomalies: Examining the Strange situation an attachment Q-Sort. Infant Mental Health Journal, 23(6), 625-642.

Condon, J.T. (1985). The parenthal-foetal relationship - a comparison of male and female espectant parents. Journal of Psychosomatic Obstetrics and Gynaecology, 4, 271-284.

Deutsch, H. (1945). The Psychology of Women, Vol. 2: Motherhood. New York: Green and Stratton.

Fédida, P. (1978). L'absence. Paris: Gallimard.

Feeney, S. (2000). Implications of attachment style for paterns of health and illness. Child: Care, Health and development, 26(4), 277-288.

Ferrari, A. (2003). Tornar-se mãe: a constituição da maternidade da gestação ao primeiro ano de vida do bebê. Tese de Doutorado não publicada, Programa de Pós-Graduação em Psicologia do Desenvolvimento, Instituto de Psicologia, Universidade Federal do Rio Grande do Sul, Porto Alegre.

Ferrari, A., Piccinini, C., \& Lopes, R. (2007). O bebê imaginado na gestação: aspectos teóricos e empíricos. Psicologia em Estudo, 12(2), 305-313.

Franco, V., \& Apolonio, A. (2002). Desenvolvimento, resiliência e necessidades das famílias com crianças deficientes. Revista Ciência Psicológica, 8, 40-54.

Franco, V. (2009). Adaptação das famílias de crianças com perturbações graves do desenvolvimento - contribuição para um modelo conceptual. INFAD - International Journal of Developmental and Educational Psychology, XXI(2),179-184.

Freud, S. (1992). Luto e melancolia. In S. Freud, Novos Estudos, 32 (pp. 128-142). São Paulo: Cebrap. (Trabalho original publicado em 1917).

Hornstein, L. (Org.). (1994). Cuerpo, história, interpretacion - Piera Aulagnier: de lo originario al proyecto identificatorio. Buenos Aires: Paidós.

Humphreys, D. (2013). Figuras de la depresión y figurabilidad melancólica. Precisiones fenomenológicas y psicopatológicas respecto de la melancolía y la depression. Rev. Latinoam. Psicopat. Fund., 16(3), 398-410.

Kibrit, B. (2013). Possibilidades e desafios na inclusão escolar. Rev. Latinoam. Psicopat. Fund., São Paulo, 16(4), 683-695.

Lebovici, S. (1987). A mãe, o bebê e o psicanalista. Porto Alegre: Artes Médicas.

McCubbin, M., \& McCubbin, H. (1993). Families coping with illness: the resilience model of family stress, ajustment and adaptation. In C.B. Denielson, Families, Health and Illness: Perspectives on Coping and Intervention (pp. 21-63). Madison: Univ. of Wisconsin. 
Pedro, J.C. (1985). Relação mãe-filho. Influência do contato precoce no comportamento da diade. Lisboa: Imprensa Nacional. Casa da Moeda.

Pianta, R., Marvin, R., \& Morog, M. (1999). Resolving the Past and Present: Relations with Attachment Organization. In J. Solomon, \& C. George, Attachment Disorganization, New York: Guilford Press.

Rivera, T. (2012). Entre dor e deleite. Novos estudos. Cebrap, 94, São Paulo.

Sá, E. (1996). Abandono e adopção. Coimbra: Almedina.

Seligman, M. (1999). Child disability and the family. In V. Schwean, D. Salofske, Handbook of Psychosocial Characteristics of Exceptional Children. New York: Springer.

Stern, D. (1997). A constelação da maternidade - o panorama da psicoterapia pais/bebê. Porto Alegre: Artes Médicas.

Stern, D., Brunschwiler-Stern, N., \& Freeland, A. (1999). El nascimiento de una madre. Madrid: Paidós.

Teixeira, M.C. (2013). Onde estava antes de ter nascido? Um estudo sobre a vinculação prénatal. Tese de doutoramento não publicada. Universidade de Évora, Évora, Portugal.

\section{Resumos}

(Passion-pain-passion: pathos, morning and melancholy on the occasion of a child born with disabilities)

The birth of a child with a severe developmental disorder affects, as a crisis, the development of its parents. The loss of the idealized child requires mourning. However, the emotional identification with the pathos-passion becomes an obstacle to that process and to the bonding to the newborn, who has its qualities and disabilities, and who may not be able to occupy any space in the emotional life of its parents, since they are struggling with their pathos-pain. This paper discusses ways to escape melancholy and alternatives to manage the emotional distress, encouraging parental engagement and attachment to disabled children.

Keywords: Disability, attachment, melancholy, mourning

(Passion-douleur-passion: pathos, deuil et mélancolie à la naissance d'un enfant handicapé)

La naissance d'un enfant avec un trouble grave du développement affecte, en tant que crise, le développement des parents. La perte de l'enfant idéalisé demande l'élaboration du deuil. Cependant, le lien émotionnel avec la pathos-passion originale devient un obstacle à ce processus et à l'attachement au nouveau-né, avec ses qualités et insuffisances. Celui-ci risque en effet de rester exclu de la vie affective de ses parents, étant donné qu'ils sont en train d'élaborer leur pathos-douleur. Dans cet article, nous discutons comment échapper à la mélancolie et les alternatives d'élaboration de la 


\section{CONFERÊNCIA}

détresse émotionnelle en vue de l'engagement des parents et de leur attachement à l'enfant handicapé.

Mots clés: Handicap, attachement, mélancolie, deuil

(Pasión-dolor-pasión: pathos, luto y melancolía en el nacimiento del niño con discapacidad)

El nacimiento de un hijo con un trastorno grave de desarrollo afecta, como una crisis, el desarrollo de los padres. La pérdida del hijo idealizado requiere la elaboración de un duelo. Sin embargo, la conexión emocional con el primer pathos-pasión se convierte en un obstáculo para este proceso y, más que todo, en un nuevo vínculo con el bebé nacido y real, con sus cualidades y discapacidades, un bebé que corre el riesgo de no tener un espacio en la vida emocional de sus padres que luchan con su pathos-dolor. En este trabajo se discuten los resultados del lado melancólico y las alternativas de gestión de la angustia emocional con miras a la inversión parental y al compromiso con el niño con discapacidad.

Palabras clave: Discapacidad, vínculo, melancolía, duelo

(Leidenschaft-Schmerz-Leidenschaft: Pathos, Trauer und Melancholie anlässlich der Geburt eines behinderten Kindes)

Die Geburt eines Kindes mit einer schweren Entwicklungsstörung markiert, als Krise, den evolutionären Weg der Eltern. Der Verlust des idealisierten Kindes erfordert Trauerarbeit. Die emotionale Bindung an die ursprüngliche Pathos-Leidenschaft behindert jedoch diesen Prozess, aber auch den Beginn der neuen Beziehung zum geborenen und realen Baby, mit seinen Qualitäten und Grenzen. Es besteht die Gefahr, dass das Kind vom Gefühlsleben der Eltern ausgeschlossen bleibt, da diese von ihrem Pathos-Schmerz absorbiert sind. Dieser Artikel diskutiert Auswege aus der Melancholie und die Alternativen für die Verarbeitung der emotionalen Belastung im Hinblick auf die elterliche Investition und Bindung zu behinderten Kindern.

Schlüsselwörter: Behinderung, Bindung, Melancholie, Trauer

（悲伤-痛苦-悲伤：残疾孩子的出生给父母带来的伤感，默哀和忧郁）

一个有严重智力障碍的孩子的出生会给家长带来严重的精神危机。父母失去 了理想化的孩子，因而会陷入悲伤和痛苦。家长的伤感和默哀，会影响到他们对 自己的残疾孩子重新建立联系，孩子甚至有被父母的情感抛弃的危险。本文讨论 能够帮助家长走出哀痛和忧郁, 重建对残疾孩子的情感联系的一些方法, 重点是 对家长进行心理疏导，使他们重建对自己残疾孩子的喜爱。

关键词: 残疾, 喜爱, 忧郁, 默哀 
Citação/Citation: Franco, V. (2015, junho). Conferência - Paixão-dorpaixão: pathos, luto e melancolia no nascimento da criança com deficiência. Revista Latinoamericana de Psicopatologia Fundamental, 18(2), 204-220.

Editores do artigo/Editors: Prof. Dr. Manoel Tosta Berlinck e Profa. Dra. Sonia Leite

Recebido/Received: 8.10.2014/ 10.8.2014 Aceito/Accepted: 25.10.2014 / 10.25.2014

Copyright: (C) 2009 Associação Universitária de Pesquisa em Psicopatologia Fundamental/ University Association for Research in Fundamental Psychopathology. Este é um artigo de livre acesso, que permite uso irrestrito, distribuição e reprodução em qualquer meio, desde que o autor e a fonte sejam citados / This is an open-access article, which permits unrestricted use, distribution, and reproduction in any medium, provided the original authors and sources are credited.

\section{Vitor Franco}

Doutor em Psicologia Clínica; Professor do Departamento de Psicologia da Universidade de Évora (Portugal).

Apartado 94

7002-554 Évora

Portugal

e-mail: vfranco@uevora.pt 